\title{
Modeling urban expansion policy scenarios using an agent-based approach for Guangzhou Metropolitan Region of China
}

\author{
Guangjin Tian $^{1}$ and Zhi Qiao $^{1}$
}

\begin{abstract}
Policy makers and the human decision processes of urban planning have an impact on urban expansion. The behaviors and decision modes of regional authority, real estate developer, resident, and farmer agents and their interactions can be simulated by the analytical hierarchy process (AHP) method. The driving factors are regressed with urban dynamics instead of static land-use types. Agents' behaviors and decision modes have an impact on the urban dynamic pattern by adjusting parameter weights. We integrate an agent-based model) (ABM) with AHP to investigate a complex decision-making process and future urban dynamic processes. Three policy scenarios for baseline development, rapid development, and green land protection have been applied to predict the future development patterns of the Guangzhou metropolitan region. A future policy scenario analysis can help policy makers to understand the possible results. These individuals can adjust their policies and decisions according to their different objectives.
\end{abstract}

Key Words: agent-based model; analytical hierarchy process; Guangzhou; policy makers; scenario analysis

\section{INTRODUCTION}

China's rapid urbanization has attracted worldwide attention. According to the Urban and Rural Planning Law of the People's Republic of China issued in 2007, the objective of urban planning is to strengthen the management of urban areas and to improve the human living environment. Urban planning in China is considered to be important, and a legislative authority for urban development has been established. Strategic spatial development policy is a major component of urban planning, and it determines the spatial pattern of urban development. Its objective is to change the organization of the spatial environment to meet societal demands. Urban planning has a big impact on the urbanization process. For example, a strategic spatial development policy will have an impact on the overall pattern of urban expansion, whereas the construction of an economic development zone will stimulate urban growth in specific urban areas.

Modeling urban systems can improve our understanding of the mechanisms of urban expansion (Li and Liu 2007, Tian et al. $2011 a, b)$. Social and economic factors are the main driving forces behind urban expansion and land-use dynamics (Verburg et al. 1999, 2002, Tian et al. 2011a,b). Urban dynamic simulations and landscape dynamics in Chinese urban areas have been studied extensively (Tian et al. 2005, 2007a, b, 2011a, b, Li and Liu 2007, Xie et al. 2007, He et al. 2008, Li and Liu 2008). Land-use dynamic models have been used to study land use and the factors driving changes in land use using empirically quantified relationships (Verburg et al. 1999, 2002, Seto and Kaufmann 2003), but they cannot reflect the behavior of decision makers. The drawbacks of traditional spatial interactions and discrete choice models are their poor representation of spatial and socioeconomic details as well as urban simulation dynamics (Parker et al. 2003, An et al. 2005). Moreover, these interactions have apparent limitations in simulating the decisions and behavior of agents (Xie et al. 2007, Li and Liu 2007, Li and Liu 2008, Tian et al. 2011b).

The cellular automata (CA) method has been widely used to simulate urban dynamics, but it is not suitable for reflecting the behavior of individuals and capturing the macroscale political, social, cultural, and economic driving forces behind urban expansion (Xie et al. 2007, Li and Liu 2008, Gong et al. 2009, Tian et al. 2011b). However, the behavior of individuals and their interactions with the environment are important for understanding and modeling urban ecosystems (Bousquet and Page 2004). The agent-based model (ABM) paradigm has emerged from the fields of complexity, chaos, cybernetics, and $\mathrm{CA}$, and has been widely used to simulate complex systems ranging from engineering to mathematics, social science, and economics in the 1990s (Heath et al. 2009). It has also been applied to urban expansion and land-use dynamics as a powerful simulation technique (Janssen 1998, 2000, Ligtenberg 2001, 2004, Lempert 2002, Parker et al. 2003, Sengupta and Bennet 2003, Bousquet and Page 2004, An et al. 2005, Xie et al. 2007, Li and Liu 2008). Although CA and ABM are limited in terms of their geographic analysis, when they are used as an isolated tool, the integration of $\mathrm{CA}$ with $\mathrm{ABM}$ produces better simulation results (Torrens and Benenson 2005, Li and Liu 2007). This integration combines urban dynamics and social processes and incorporates human decision making into land use in a mechanistic and spatially explicit way (Lempert 2002, Matthews et al. 2007). It offers a conceptual framework for incorporating multiple actors into dynamic spatial decision-making models and has been employed to simulate human-environment interactions and ecosystem management (Parker et al. 2003, Sengupta and Bennet 2003, Torrens 2003, Bousquet and Le Page 2004, Ligtenberg et al. 2004, An et al. 2005). The advantages of integration are apparent at not only the spatial neighborhood, or cell states of $\mathrm{CA}$, scale but also in the interactions between the driving factors of urban development and their environment, which must be considered to forecast urban sprawl with a high level of accuracy (Loibl and Toetzer 2003).

The urbanization process is influenced by a number of autonomous entities such as the regional authority, urban planners, real estate developers, residents, and farmers. During a complex social process, these agents will interact with each other directly and indirectly. Rather than study them as individuals, the 
agents are typically classified into organizations and interest groups (Tian et al. 2011b). Their behavior, i.e., actions and interactions, determines urban policy and the evolution of the whole process. The ABM model provides a compelling account of group pattern formation, contagion, and cooperation, and can be used to predict, manipulate, and improve upon collective behavior (Goldston and Janssen 2005). A major problem with $\mathrm{ABM}$ is how to define agent properties using empirical data $(\mathrm{Li}$ and Liu 2007). The analytical hierarchy process (AHP) has been used to derive behavior-oriented transition rules for CA (Wu 1998), but it has not been used to extract agent preferences and policies. How to avoid unfair or human factors in determining agent preferences and behavior needs to be considered. The main objective of our study was to extract important parameters through a regression model and to adjust their weightings for different policies and objectives using ABM and AHP techniques. The combination of AHP and ABM is suitable for the simulation of different agent interactions and negotiations. Scenario analysis is a useful spatial exploratory tool for evaluating the potential impacts of implementing different land-use policies.

As the capital city of Guangdong Province, Guangzhou is the political, economic, scientific, educational, and cultural center of the Pearl River Delta in China. Because of its rapid economic development, Guangzhou has become one of the fastest growing cities in China. Unprecedented urban dynamics have been witnessed in the region following the implementation of 'reform and opening-up' policies. The reform and opening-up policies refer to the program of economic reforms called 'socialism with Chinese characteristics' in the People's Republic of China, which were initiated in December 1978 by reformists within the Communist Party of China led by Deng Xiaoping. The rapid urbanization process has resulted in traffic congestion, unaffordable housing, loss of open space, water pollution, urban heat islands, and loss of agricultural land (Turner 1994, Yeh and Li 1998, Lambin et al. 2000, Ligtenberg et al. 2001, Waddell 2002, Tian et al. 2002, 2005, 2007a, b, 2010, 2011a, b, Li and Liu 2007 , Li and Liu 2008). Urbanization processes are complex, and the physical, ecological, and social components of the entire system must be considered (Zipperer et al. 2000). The future pattern of urban development of the Guangzhou metropolitan region has been predicted using a combination of ABM with logistic regression. This projection of the urban dynamic process will help managers to understand its environmental impact and to create sustainable development policies for the Guangzhou metropolitan region.

\section{STUDY AREA AND DATA SOURCES}

\section{Study area}

Guangzhou is located in southern China between $112^{\circ} 57^{\prime}-114^{\circ}$ $3^{\prime} \mathrm{E}$ and $22^{\circ} 26^{\prime}-23^{\circ} 56^{\prime} \mathrm{N}$. It is the geometric center of the Pearl River Delta and is bounded by the Pearl River to the east and south. The Pearl River is China's third largest river and it runs through Guangzhou. Guangzhou is called 'China's South Gate' because of its geographical location. Its northern and northeastern areas are hilly or mountainous and the center is also mountainous. The alluvial plain of the Pearl River Delta is located south of the city.
Covering an area of appropriately $7434.4 \mathrm{~km}^{2}$, Guangzhou is home to more than 11 million people, including a registered population of 7.38 million and a transient population of 3.7 million (Guangdong Statistics Bureau 2006). In June 2000, two former cities at the county level, Panyu and Huadu, became two administrative districts under Guangzhou's jurisdiction. Guangzhou consists of 10 administrative districts and 2 cities at the county level (Fig. 1).

Fig. 1. The administrative districts and counties of Guangzhou metropolitan region.

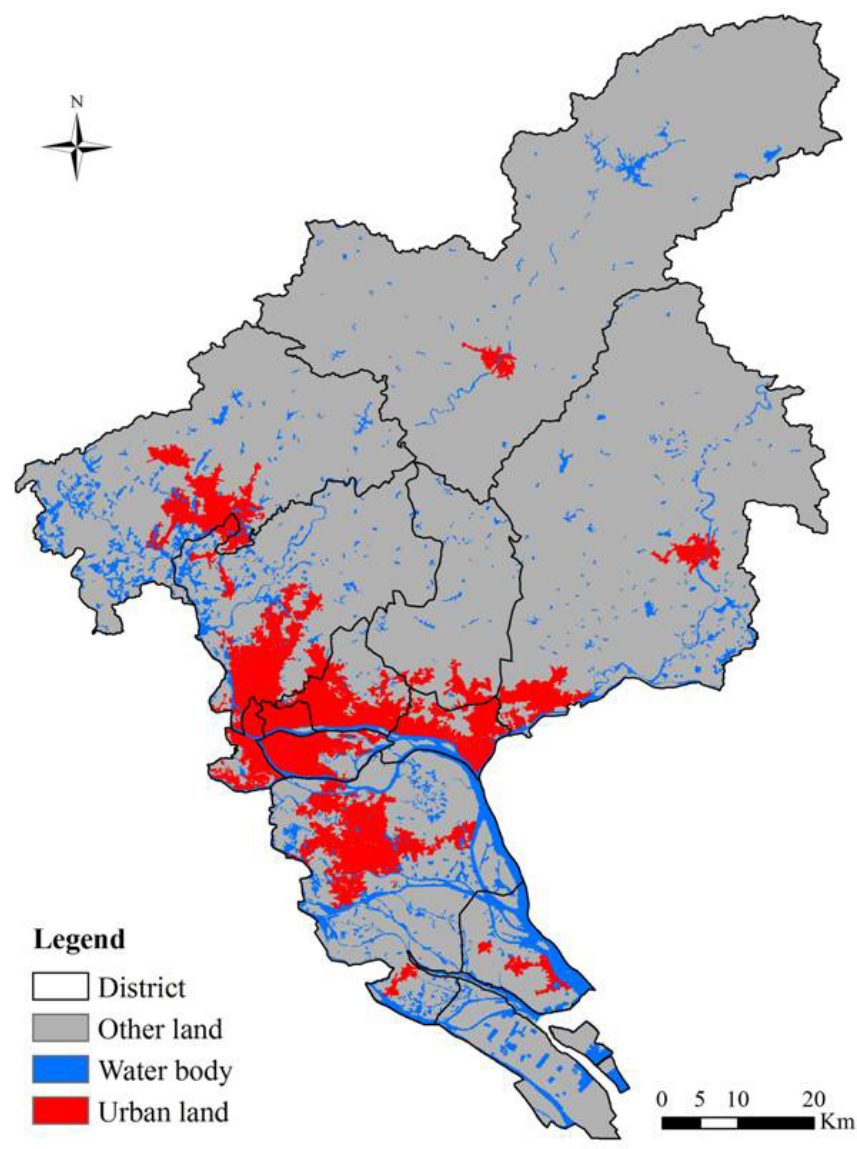

\section{Data sources and processing}

Landsat Enhanced Thematic Mapper (ETM) images from 2000 and 2005 were interpreted to obtain land-use data from the Guangzhou metropolitan area. We used cloud-free images taken during the winter when there was less vegetation. After radiometric correction, the 5, 4, and 3 bands of the chosen images were RGB false-color composed.

There are several methods for detecting changes, such as image differencing, principal components transformation, tasseled cap transformation, Gramm-Schmidt transformation, image classification, and post-classification comparison (Fung and LeDrew 1988, Quarmby and Cushnie 1989, Wang 1993, Collins and Woodcock 1994, Ji et al. 2001). Post-classification comparison was used to 
Fig. 2. Agent-based model framework.

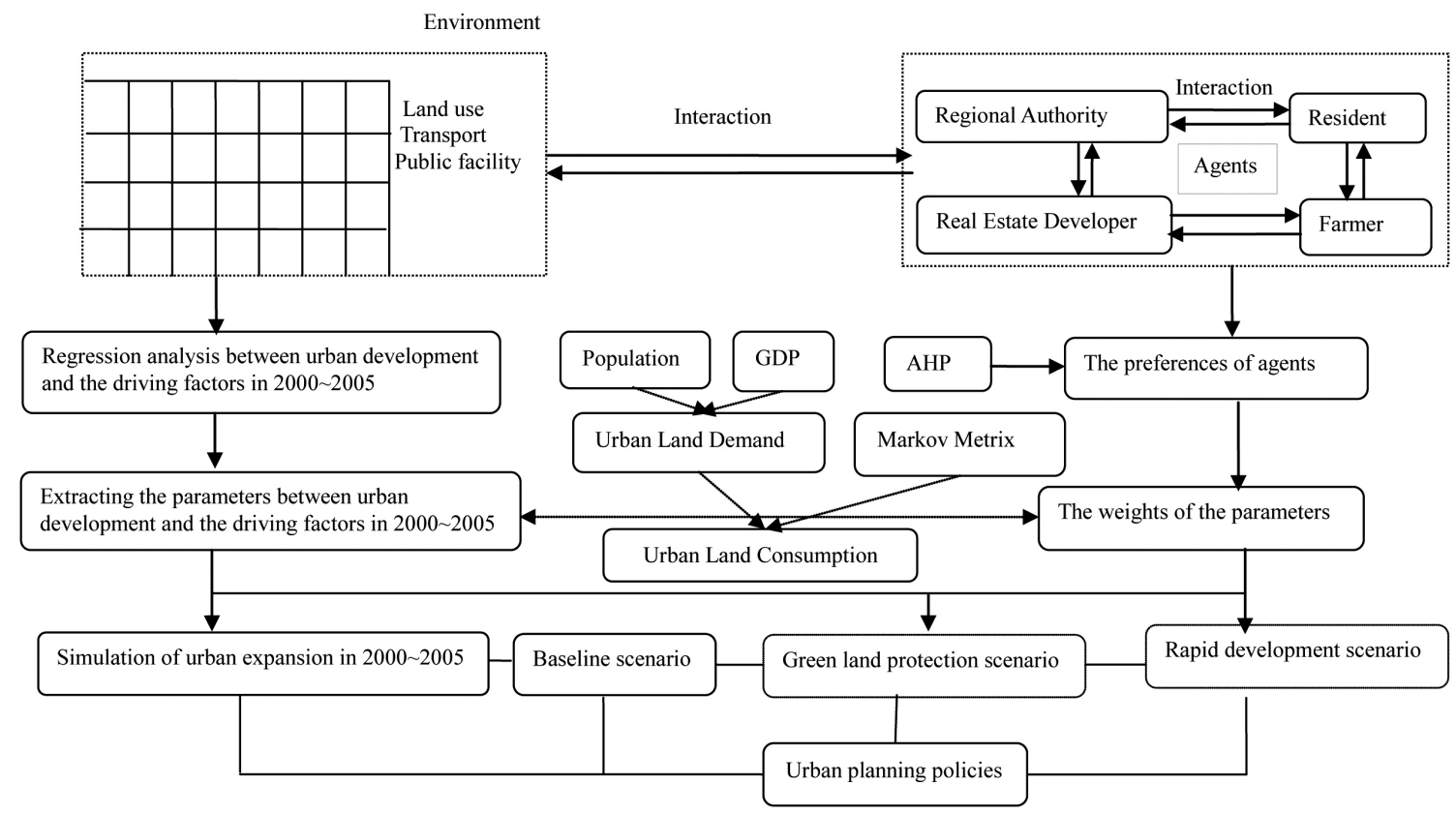

identify the number and location of changes. A prior classification was performed before making a comparison. For the first grade, the land use was classified as cropland, forest, grassland, water body, built-up land, or unused land. For the second grade, builtup land was reclassified into urban land, rural residential land, construction, or mining land (Liu et al. 2003, 2005a, b). A comparison between two images from 2000 and 2005 decreased the errors originating from the misclassification of independently classified images (Fung 1990). Enhanced Thematic Mapper image interpretation was undertaken using a 1:100,000 topographical map, river and soil maps, and other available maps. Land-use vector data were projected onto a uniform Gauss-Kruger coordinate system. The central longitude of the projection system was $105^{\circ} \mathrm{E}$, and the double standard latitudes were $25^{\circ} \mathrm{N}$ and $47^{\circ}$ $\mathrm{N}$.

The land cover data sets covered the Guangzhou administrative district. The vector land-use data were converted into a $100 \times 100$ m grid. Land cover was classified as cropland, forest, grassland, water body, urban land, rural residential land, industrial and mining land, or unused land (Tian et al. 2005, 2007a, b, 2010). Using this classification, the seven land-use types, i.e., cropland, forest, grassland, water body, rural residential land, industrial and mining land, and bare land, were converted into urban land. We outlined the cropland, forest land, rural residential land, and other land that were converted into urban land for this model.

\section{METHODOLOGY}

The ABM supports the study and analysis of decision making, local-global interactions, self-organization, emergence, and the effects of heterogeneity in a simulated system (Heath et al. 2009). The main components of an ABM can be defined as agents, their environment, and the mechanisms between them. An agent is an entity with a set of characteristics relating to autonomy, social ability, reactivity, and proactiveness (Wooldridge and Jennings 1995, Triantakonstantis and Mountrakis 2012). The environment enables agents to have perceptions and actions. The interaction mechanism includes both a direct and indirect exchange of information between the entities, which is realized through the perception by an agent of the effects of another agent's action (Bandini et al. 2009). The interdependencies and feedback between agents and the environment are integrated (Parker et al. 2003, An et al. 2005).

The model used in this study integrated ABM with AHP to simulate policy scenarios (see Online Resource 1, Fig. 2). ArcGIS 9.3 was used to provide inputs for the simulation and calibration of urban development. The ABM and AHP components enabled urban policies and the interactions among the different agents, which affect urban development, to be assessed (Fig. 2). The geographic information system and regression models were used to simulate the spatial urban development process. Urban planning and policies were used to help project urban land expansion into different regions.

\section{Projecting urban land demand}

Urban planning and policy

Urban planning plays a key role in urban expansion. The urban plan for Guangzhou has been revised several times. The General Strategic Conceptual Plan's outline of Guangzhou Urban Construction, from 2000, states that the spatial development strategy is, "To expand in the southern area, optimize in the northern area, develop in the eastern area, and link to the western area" (Guangzhou Urban Planning Bureau 2000). The General Plan of Guangzhou (2001-2010) was revised in 2005. The southern and eastern regions of Guangzhou are destined for development. Government policy and market forces have led to rapid growth in the southern areas (Yu and Ng 2007). According 
to the spatial development strategy, urban land consumption in the Panyu and Nansha districts is projected for the future. In our model, urban planning determined the urban land demand in different districts and cities.

\section{Linear regression and Markov matrix}

Urban development depends on urban land demand. The key drivers of urban development at the regional level are economic development and population growth. There are large spatial variances in the multiple development nuclei of the different districts of the Guangzhou metropolitan area. The five districts, i.e., Liwan, Yuexiu, Haizhu, Tianhe, and Huangpu, were combined into the central district (Fig. 1). The urban development of these districts was individually simulated in the following order: Baiyun, Luogang, Panyu, Nansha, and Huadu, and the cities of Zengcheng and Conghua. Urban land from each district was regressed against the independent variables in Equation 1.

$$
U L_{i}(t)=\alpha_{i} P_{i}(t)+\beta_{i} G_{i}(t)+\varepsilon
$$

Where $U L_{i}(\mathrm{t})$ is the urban land in the ith district and county, $P_{i}$ (t) is the population in $i$ district and county, $G_{i}(\mathrm{t})$ is the Gross Domestic Product (GDP) in $i$ district and county, $\alpha$ is the population parameter, $\beta$ is the GDP parameter, and $\varepsilon$ is random error.

This projection cannot extract urban land area from cropland, forest, rural residential land, and other land. We used the Markov matrix to project urban land sources.

\section{The spatial regression model and its driving factors}

ArcGIS 9.3 was used to calculate the local interactions between physical factors. Each cell in a geographic space was defined by $(x, y)$ coordinates. The environment was represented as a twodimensional grid and each cell had attributes and states. The environmental layers included spatial data for land use, the surrounding environment, general public facilities, and education. In this model, we considered the distance to railways, roads, schools, hospitals, and other factors. The constraining factors included water bodies and large patches of forest (Fig. 2). Roads and railways are important factors because they represent a location characteristic, which permits access to a place. If a site is close to roads and railways, it is more likely to be developed. The presence of a railway will decrease the transportation costs for factories. The distance to schools, hospitals, and entertainment centers are environmental factors that influence urban expansion. Sites will be more attractive for residents if they are close to schools, hospitals, and entertainment centers. The presence of a hospital within a neighborhood encourages individuals to buy houses within that neighborhood. Schools, hospitals, and entertainment centers will encourage urban expansion.

Land use is one of the most important factors in urban simulations. This factor provides the basic environment for agents to make decisions. Agents will display different decision-making behavior in relation to different types of land use. In the data sets, there were eight land-use types: cropland, forest, grassland, water bodies, rural residential land, industrial and mining land, bare land, and urban land.
The relationship between the probability of urban expansion and its driving factors has been evaluated by the use of logistic regression models (Geoghegan et al. 2001, Gobin et al. 2001, Serneels and Lambin 2001, Verburg et al. 2002, Tian et al. 2011 $a, b$ ). Our model took a number of proximity variables into account (Wu 2002, Li and Liu 2007).

Various factors, such as the distance to roads, railways, schools, hospitals, and entertainment centers were estimated using a logistical regression model. The following equation was used:

$$
\log \left(\frac{P_{i j, A}^{t}}{1-P_{i j, A}^{t}}\right)=\beta_{0}+\beta_{1} X_{i j, 1}^{t}+\beta_{2} X_{i j, 2}^{t}+\cdots+\beta_{n} X_{i j, k}^{t}
$$

Where $P_{i j, A}^{t}$ is the urban development probability by physical factors using the regression model, $\beta_{0}$ is a constant, and $X_{i j, k}^{t}$ is the coefficient of driving factor $k$ in cell $i j$ at time $t$.

In the previous study, the probability of land use occurrence was regressed with the driving factors (Verburg et al. 2002, Tian et al. $2011 b$ ). In our study, the urban expansion occurrence is regressed.

The physical constraints of urban development and the percentage of urban cells in the neighborhood will influence the probability of urban development, which was expressed as follows:

$$
P_{i j}^{t}=P_{i j, A}^{t} \cdot P_{i j, c o n}^{t} \cdot P_{i j, \Omega}^{t}
$$

Where $P^{t}{ }_{i j}$ is the urban development probability for the cell in $i j$; $P^{t}{ }_{i j, c o n}$ is the urban development probability by the constraint factors, the value of zero will be assigned to all the water and large forest patch cells; and $P_{i j, \Omega}^{t}$ is the urban development probability of neighborhood factors.

\section{The agent-based model (ABM)}

Urban expansion is the result of a combination of human behavior, decisions, and policies (Tian et al. 2011b). Interactions among agents are the disaggregated results of negotiation and communication between agents (Parker et al. 2003). The behavior of agents is based on their preferences, knowledge, and the environment (Tian et al. 2011b). All agents observe and perceive the spatial environment, then judge its spatial suitability according to their preferences, and decide if the cells will be urbanized. Hence, the preferences of the agents are the key factors influencing their behavior.

As agents, regional authorities, real estate developers, residents, and farmers have different preferences. The preferences of the regional authority are to make maximum use of land resources and stimulate economic development. These agents want to stimulate economic development that is concentrated around existing urban conglomerates, but prohibit development on large patches of forest and water bodies. They prefer that urban expansion occurs on agricultural land.

The regional authorities will decide if an application for urban development is approved. The real estate developer builds houses to meet residential demand. The regional authority allocates land for the development of residential districts.

The preference of the real estate developer is to maximize their profit (Li and Liu 2008). Real estate developers prefer to utilize major roads and infrastructure such as schools, hospitals, and entertainment centers. 
The objective of residents is to locate the best place to live with the lowest price and best environment. The residents will prefer a site that is close to hospitals, schools, and entertainment centers.

The preference of farmers is to protect high-production cropland. These agents hope to keep a specific amount of cropland for cultivation and prefer urban development to occur far away from highly productive cropland. These agents will interact with each other (Fig. 2). There are some conflicts between agent objectives. For example, the farmer agents will protect cropland whereas the real estate developers and regional authorities hope to use the cropland for urban development. These conflicts were manifested through the different objectives. They were resolved by adjusting the weighting of the parameters.

Agent behavior influences the rate and quantity of urban development. Agent preference influences urban expansion through the adjustment of the weightings of the various driving factors (Tian et al. 2011b). The final driving factor preferences were decided by a combined interaction process. Each group of agents has a unique set of preferences for selecting specific sites for urban expansion.

The AHP was used to extract agent preferences, and can be considered to be a decision-aiding method (Saaty 1980). The different preferences of the regional authority, real estate developer, resident, and farmer agents present different policy scenarios. A decision maker bases their judgment on preference, knowledge, and experience, and then makes decisions. The strength of this model is that it organizes the driving factors in a systematic way and provides a simple solution for the decisionmaking process (Skibniewski 1992). Pairwise comparisons have been applied to acquire agent preferences for the driving factors (Saaty 1980, Wu 1998, Al-S. Al-Harbi 2001). Weighting calculations and consistency measurements were studied and implemented in a GIS environment (Saaty 1980, Wu 1998).

The probability of urban development is the combination of behaviors on the part of the regional authority, real estate developer, resident, and farmer agents.

The combined preferences $P R^{k}$ of these agents for driving factor $i$ are as follows:

$$
P R^{k}=\frac{\left(P R_{R A}^{k}\right)^{\frac{1}{3}} \cdot\left(P R_{R E}^{k}\right)^{\frac{1}{3}} \cdot\left(P R_{R D}^{k}\right)^{\frac{1}{3}}}{P R_{F A}^{k}}
$$

Where $P R^{k}$ is the combined preferences of the regional authority, real estate developer, resident, and farmer for driving factor $k$. $P R_{\mathrm{RA}}^{k}, P R_{\mathrm{RE}}^{k}, P R_{\mathrm{RD}}^{k}, P R_{\mathrm{FA}}^{k}$ are the preferences of the regional authority, real estate developer, resident, and farmer for factor $k$, respectively. One-third of the preference of the regional authority, real estate developer, resident, and farmer can eliminate the productive effect of the three factors considered by decision makers. The farmer's preference is negative in relation to the preference of the regional authority, real estate developer, and resident. Hence, the farmer's preference is the denominator of Equation 4.

Integrated agent-based model (ABM) and logistic regression Agent behavior will influence the probability of urban development by adjusting the parameter weightings of the driving factors (Tian et al. 2011b). $\log \left(\frac{P_{i j, A}^{t}}{1-P_{i j, A}^{t}}\right)=\beta_{0}+W_{1} \beta_{1} X_{i j, 1}^{t}+W_{2} \beta_{2} X_{i j, 2}^{t}+\cdots+W_{n} \beta_{n} X_{i j, k}^{t}$

The combined behavior of the different agents determines the weightings of the parameters in Equation 5. Using Eqation 3, we calculated the probability of urban development for every cell. The Monte Carlo method was used to determine the final selection of a location for urban development ( $\mathrm{Wu}$ and Webster 1998, Li and Liu 2007).

The cells with the highest probability of urban development would be developed until the acreage of the cells reached the urban land demand (Fig. 2).

\section{MODEL IMPLEMENTATION AND RESULTS}

\section{Urban land expansion in the Guangzhou metropolitan region}

Regression analysis was used to predict the urban land demand for every district and county. Because GDP and population data sets were available for every year with discrete urban land data, the urban land was regressed first by population with year $t$ (Eq. 6), then by GDP with year $t$ (Eq. 7), and finally by both population and GDP (Eq. 8).

$$
\begin{gathered}
P_{k}(t)=0.1894 t^{2}-753.23 t+749132 \\
R^{2}=0.9855 . \\
G_{k}(t)=217.92 t-434562 \\
R^{2}=0.7555 . \\
U L_{k}(t)=2.9365 P_{k}(t)-0.0162 G_{k}(t)-748.8519 \\
R^{2}=0.9853 .
\end{gathered}
$$

The population and GDP of the central district were projected for 2020 according to Equations 6 and 7. The urban land in the central district was projected using Equation 8. The urban development of $k$ district or county was projected using Equation 9.

$$
\Delta U L_{k}(t)=U L_{k}(t)-U L_{k}(t-1)
$$

Similarly, the population, GDP, and urban development were projected individually for the districts of Baiyun, Luogang, Panyu, Nansha, Huadu, and cities of Zengcheng and Conghua. The urban development of Guangzhou City was calculated as the total of the eight districts and cities.

$$
\Delta U L(t)=\sum_{k=1}^{8} \Delta U L_{k}(t)
$$

The level of urban development in every district and county was allocated to the cells according to the probability of development. From the regression analysis, we projected the amount of urban land in every district and county of the Guangzhou metropolitan area (Fig. 3). The regression analysis indicated that, between 2005 and 2020 , the area of urban land would increase by $188.95 \mathrm{~km}^{2}$ 
in the central district, $130.28 \mathrm{~km}^{2}$ in Baiyun, $26.27 \mathrm{~km}^{2}$ in Luogang, $40.22 \mathrm{~km}^{2}$ in Huadu, $97.85 \mathrm{~km}^{2}$ in Zengcheng, and 1.61 $\mathrm{km}^{2}$ in Conghua (Fig. 3). By using the strategy of urban spatial development planning, the projected consumption of urban land increased by $81.59 \mathrm{~km}^{2}$ in the Panyu district and $30.91 \mathrm{~km}^{2}$ in the Nansha district between 2005 and 2020.

Fig. 3. The urban land in the Guangzhou metropolitan region in $2000 \sim 2020\left(\mathrm{~km}^{2}\right)$.

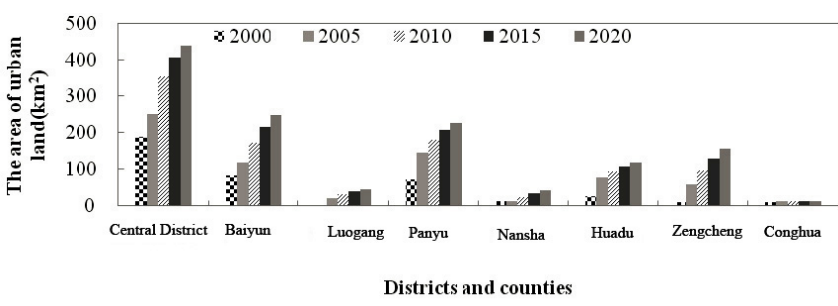

The projection cannot extract urban land area from cropland, forest, rural residential land, and other land. The probability of land-use conversion from cropland, forest, rural residential land, and other land to urban land was significantly different in each district. Therefore, we calculated the area converted to urban land from other land in each district. However, the projection only provided the total area of new urban land. We used a Markov matrix to project urban land sources. A Markov matrix was used to calculate the area of urban land that had encroached on other land-use types based on the conversions between 2000 and 2005. We calculated the sources of urban development for every district and county, based on the projection of urban land and the Markov matrix results for the period between 2005 and 2020 (Table 1).

Table 1. Markov transition probability matrix in central district between 2000 and 2005 .

\begin{tabular}{lccccc}
\hline \hline Land use & $\begin{array}{l}\text { Cropla- } \\
\text { nd }\end{array}$ & $\begin{array}{c}\text { For- } \\
\text { est }\end{array}$ & $\begin{array}{c}\text { Rural residential } \\
\text { land }\end{array}$ & $\begin{array}{c}\text { Other } \\
\text { land }\end{array}$ & $\begin{array}{c}\text { Urban } \\
\text { land }\end{array}$ \\
\hline Cropland & 0.56 & 0 & 0 & 0.01 & 0.43 \\
Forest & 0 & 0.85 & 0.02 & 0.01 & 0.12 \\
Rural residential & 0 & 0 & 0.54 & 0 & 0.46 \\
land & & & & & \\
Other land & 0 & 0 & 0 & 0.97 & 0.03 \\
Urban land & 0 & 0 & 0 & 0 & 1.00 \\
\hline
\end{tabular}

A Markov matrix, as a simple homogeneous chain, was proposed by Markov in 1906. A Markov chain is a sequence of random variables $X_{1}, X_{2}, X_{3}, \ldots, X_{k}$ with the Markov property. In case we acquire initial event $X_{k}=\alpha$ and the probabilities $P_{\alpha}^{k}$ of the event $X_{k}=\alpha$, the probability $P^{(k+1)}$ of the event $X_{k+1}{ }^{\alpha}=\beta$ could be calculated by the simple formula (Basharin et al. 2004):

$$
P_{\beta}^{(k+1)}=\sum_{\alpha} p_{\alpha}^{k} p_{\alpha, \beta}
$$

Finally, the projected conversion of cropland, forest, rural residential land, and other land to urban land in 2005 2020 in Guangzhou was calculated based on the Markov transition probability matrix and the total growth in the area of urban land in Guangzhou from 2000 to 2020 (Table 2).
Table 2. The projected conversion of cropland, forest, rural residential land, and other land to urban land between 2005 and 2020 in Guangzhou $\left(\mathrm{km}^{2}\right)$.

\begin{tabular}{lccccc}
\hline \hline $\begin{array}{l}\text { Districts } \\
\text { and } \\
\text { counties }\end{array}$ & $\begin{array}{c}\text { Cropland to } \\
\text { urban land }\end{array}$ & $\begin{array}{c}\text { Forest to } \\
\text { urban land }\end{array}$ & $\begin{array}{c}\text { Rural } \\
\text { residential } \\
\text { land to urban } \\
\text { land }\end{array}$ & $\begin{array}{c}\text { Other } \\
\text { land to } \\
\text { urban } \\
\text { land }\end{array}$ & Total \\
\hline Central & 75.38 & 65.90 & 39.39 & 8.28 & 188.95 \\
district & 54.45 & 32.64 & 32.97 & 10.23 & 130.28 \\
Baiyun & 7.48 & 16.49 & 2.29 & 0.01 & 26.27 \\
Luogang & 46.14 & 14.38 & 9.41 & 11.67 & 81.59 \\
Panyu & 13.01 & 13.01 & 0 & 4.88 & 30.91 \\
Nansha & 26.39 & 0.76 & 7.54 & 5.53 & 40.22 \\
Huadu & 17.60 & 57.58 & 19.81 & 2.86 & 97.85 \\
Zengcheng & 1.17 & 0.20 & 0.21 & 0.03 & 1.61 \\
Conghua & 1.17 & & & &
\end{tabular}

\section{The driving factors of the probability of urban development determined by a regression model}

Using the model, we regressed the probability of urban development in the cells with their driving factors for the period of 2000 2005. The extent of urban land in 2000 was used as the initial stage, and urban land dynamics for the period of 2000 2005 were applied to extract the $\beta$ values. The probability of urban development for each cell determined whether these areas would be developed.

In the model, we considered the distance to railways, roads, schools, hospitals, entertainment centers, and other factors (Table 3 ). The constraint factors included water bodies and large forest patches. The parameter of distance to roads, railways, schools, hospitals, and entertainment centers were estimated by a logistical regression model. In our model, the four land-use types of cropland, forest, rural residential land, and other land were converted to urban land. We extracted the $\beta$ values for the four types of land-use conversion in Equation 2. The $\beta$ values for the change from cropland to urban land are listed in Table 3. Similarly, the $\beta$ values from forest, rural residential land, and other land to urban land for the six districts and two cities were regressed, but these values are not listed here.

\section{The standardized preferences of the regional authority, real estate developer, resident, and farmer agents}

The analytical hierarchy process (AHP) method is applied in the model and uses pairwise comparisons to acquire the preferences of decision makers (Saaty 1980, Wu 1998). We rated the agent preference scores for the driving factors from 1 to 9 (Table 4). Then, we constructed a set of pairwise comparison matrices for each of the driving factors using the relative score measurement (Table 5). The agents then indicated their preferences for each decision scenario.

We synthesized the pairwise comparison matrix and obtained the priority vector for the variables (Table 6). The pairwise comparison matrix was established by dividing each matrix element by its column total. For example, the value 0.132 in Table 6 was obtained by dividing 1 (from Table 5 ) by 7.57 , or the sum of the column items in Table 6 . 
Table 3. The $\beta$ values from cropland to urban land in Guangzhou metropolitan area for baseline scenario.

\begin{tabular}{|c|c|c|c|c|c|c|c|c|}
\hline Cropland to Urban Land & Central & Baiyun & Luogang & Panyu & Nansha & Huadu & Zengcheng & Conghua \\
\hline Constant & -0.824 & & 6.152 & 1.107 & & 2.291 & 1.826 & \\
\hline Focal of urban land & 1.307 & & & 0.909 & 5.631 & 2.695 & 4.594 & 3.707 \\
\hline Distance to urban land & -37.57 & -69.359 & & -58.763 & & -17.66 & -50.549 & -346.194 \\
\hline Distance to cropland & -32.71 & & & & & & & \\
\hline Distance to forest land & 3.06 & 3.61 & & -6.759 & & 1.232 & -39.774 & 20.207 \\
\hline Distance to grassland & & -5.979 & & -11.427 & & -14.59 & 20.75 & -27.346 \\
\hline Distance to water body & 6.726 & & -11.667 & 14.672 & & 3.174 & & 38.355 \\
\hline Distance to school & & -8.11 & & -5.147 & & 4.767 & -13.675 & 48.468 \\
\hline Distance to hospital & 18.133 & & -59.409 & 12.52 & 680.198 & -25.213 & & \\
\hline Distance to entertainment & & -29.034 & & -14.963 & & 10.577 & & -128.144 \\
\hline Distance to railway & 8.098 & 69.789 & & 16.182 & & -34.662 & & \\
\hline Distance to road & -17.09 & -21.503 & -20.237 & -12.188 & & -14.718 & -26.213 & \\
\hline Digital elevation map (DEM) & & & -164.326 & & & 4.604 & & \\
\hline Slope & & & -12.181 & & & -4.419 & & -25.135 \\
\hline Aspect & & & & & & & & \\
\hline
\end{tabular}

Table 4. Pairwise comparison scale for the agent preferences.

\begin{tabular}{lccccccccccc}
\hline \hline Variables & $\mathrm{A}$ & $\mathrm{B}$ & $\mathrm{C}$ & $\mathrm{D}$ & $\mathrm{E}$ & $\mathrm{F}$ & $\mathrm{G}$ & $\mathrm{H}$ & $\mathrm{I}$ & $\mathrm{J}$ & $\mathrm{K}$ \\
\hline $\mathrm{A}$ & 1 & $7 / 5$ & 7 & $5 / 3$ & $7 / 5$ & $7 / 3$ & 1 & 1 & $7 / 5$ & 1 & $7 / 3$ \\
$\mathrm{~B}$ & & 1 & 5 & $5 / 3$ & 1 & $5 / 3$ & $5 / 7$ & $7 / 9$ & 1 & $5 / 7$ & $5 / 3$ \\
$\mathrm{C}$ & & & 1 & $1 / 3$ & $1 / 5$ & $1 / 3$ & $1 / 7$ & $1 / 9$ & $1 / 5$ & $1 / 7$ & $1 / 3$ \\
$\mathrm{D}$ & & & & 1 & $3 / 5$ & 1 & $1 / 3$ & $1 / 3$ & $3 / 5$ & $3 / 7$ & 1 \\
$\mathrm{E}$ & & & & & 1 & $5 / 3$ & $5 / 7$ & $5 / 9$ & 1 & $5 / 7$ & $5 / 3$ \\
$\mathrm{~F}$ & & & & & & 1 & $3 / 7$ & $1 / 3$ & $3 / 5$ & $3 / 7$ & 1 \\
$\mathrm{G}$ & & & & & & & 1 & $7 / 9$ & $5 / 7$ & 1 & $7 / 3$ \\
$\mathrm{H}$ & & & & & & & & 1 & $9 / 5$ & $9 / 7$ & 3 \\
$\mathrm{I}$ & & & & & & & & & 1 & $5 / 7$ & $5 / 3$ \\
$\mathrm{~J}$ & & & & & & & & & & 1 & $7 / 3$ \\
$\mathrm{~K}$ & & & & & & & & & & & 1 \\
\hline
\end{tabular}

A-Focal of urban land, B-Distance to urban land, C-Distance to cropland, D-Distance to forest land, E-Distance to grassland, F-

Distance to water body, G-Distance to railway, H-Distance to road, I-

Distance to school, J-Distance to hospital, K-Distance to entertainment.

Table 5. Pairwise comparison matrix for regional authority for the rapid development scenario

\begin{tabular}{lccccccccccc}
\hline \hline Variables & $\mathrm{A}$ & $\mathrm{B}$ & $\mathrm{C}$ & $\mathrm{D}$ & $\mathrm{E}$ & $\mathrm{F}$ & $\mathrm{G}$ & $\mathrm{H}$ & $\mathrm{I}$ & $\mathrm{J}$ & $\mathrm{K}$ \\
\hline $\mathrm{A}$ & 1 & $7 / 5$ & 7 & $5 / 3$ & $7 / 5$ & $7 / 3$ & 1 & 1 & $7 / 5$ & 1 & $7 / 3$ \\
$\mathrm{~B}$ & & 1 & 5 & $5 / 3$ & 1 & $5 / 3$ & $5 / 7$ & $7 / 9$ & 1 & $5 / 7$ & $5 / 3$ \\
$\mathrm{C}$ & & & 1 & $1 / 3$ & $1 / 5$ & $1 / 3$ & $1 / 7$ & $1 / 9$ & $1 / 5$ & $1 / 7$ & $1 / 3$ \\
$\mathrm{D}$ & & & & 1 & $3 / 5$ & 1 & $1 / 3$ & $1 / 3$ & $3 / 5$ & $3 / 7$ & 1 \\
$\mathrm{E}$ & & & & & 1 & $5 / 3$ & $5 / 7$ & $5 / 9$ & 1 & $5 / 7$ & $5 / 3$ \\
$\mathrm{~F}$ & & & & & & 1 & $3 / 7$ & $1 / 3$ & $3 / 5$ & $3 / 7$ & 1 \\
$\mathrm{G}$ & & & & & & & 1 & $7 / 9$ & $5 / 7$ & 1 & $7 / 3$ \\
$\mathrm{H}$ & & & & & & & & 1 & $9 / 5$ & $9 / 7$ & 3 \\
$\mathrm{I}$ & & & & & & & & & 1 & $5 / 7$ & $5 / 3$ \\
$\mathrm{~J}$ & & & & & & & & & & 1 & $7 / 3$ \\
$\mathrm{~K}$ & & & & & & & & & & & 1 \\
\hline
\end{tabular}

A-Focal of urban land, B-Distance to urban land, C-Distance to cropland, D-Distance to forest land, E-Distance to grassland, F-

Distance to water body, G-Distance to railway, H-Distance to road, I-

Distance to school, J-Distance to hospital, K-Distance to entertainment.
The priority vector in Table 6 was obtained by determining the row averages. For example, the priority of the first driving force in Table 6 was calculated by dividing the sum of the rows $(0.132+$ $0.094+0.019+0.057+0.094+0.057+0.132+0.132+0.094+$ $0.132+0.057)$ by the number of columns (11), to obtain the value of 0.13

The priority vector, indicated in Table 6, is given below:

$$
\left[\begin{array}{c}
0.13 \\
0.09 \\
0.02 \\
0.05 \\
\vdots \\
0.05
\end{array}\right]
$$

$$
0.13\left[\begin{array}{c}
1 \\
5 / 7 \\
1 / 7 \\
3 / 7 \\
\vdots \\
3 / 7
\end{array}\right]+0.09\left[\begin{array}{c}
7 / 5 \\
1 \\
1 / 5 \\
3 / 5 \\
\vdots \\
3 / 5
\end{array}\right]+0.02\left[\begin{array}{c}
7 \\
5 \\
1 \\
3 \\
\vdots \\
3
\end{array}\right]+\cdots+0.05\left[\begin{array}{c}
7 / 3 \\
5 / 3 \\
1 / 3 \\
1 \\
\vdots \\
1
\end{array}\right]=\left[\begin{array}{c}
1.44 \\
1.04 \\
0.20 \\
0.58 \\
\vdots \\
0.60
\end{array}\right]
$$

By dividing all the elements of the weighted sum matrices by their respective priority vector element, we obtained the following:

$$
\frac{1.44}{0.13}=11.1, \frac{1.04}{0.09}=11.6, \frac{0.20}{0.02}=10, \cdots, \frac{0.60}{0.05}=12
$$

Next, we computed the average of these values to obtain the largest eigenvalue $\lambda_{\max }$

$$
\lambda_{\max }=\frac{(11.1+11.6+10+\cdots+12)}{11}=11.05
$$


Table 6. The synthesized matrix for regional authority for the rapid development scenario.

\begin{tabular}{|c|c|c|c|c|c|c|c|c|c|c|c|c|}
\hline Variables & A & $\mathrm{B}$ & $\mathrm{C}$ & $\mathrm{D}$ & $\mathrm{E}$ & $\mathrm{F}$ & $\mathrm{G}$ & $\mathrm{H}$ & $\mathrm{I}$ & $\mathrm{J}$ & $\mathrm{K}$ & Priority Vector \\
\hline A & 0.132 & 0.134 & 0.127 & 0.123 & 0.127 & 0.127 & 0.118 & 0.153 & 0.136 & 0.127 & 0.127 & 0.13 \\
\hline B & 0.094 & 0.095 & 0.091 & 0.088 & 0.091 & 0.091 & 0.085 & 0.119 & 0.097 & 0.091 & 0.091 & 0.09 \\
\hline $\mathrm{C}$ & 0.019 & 0.019 & 0.018 & 0.018 & 0.018 & 0.018 & 0.017 & 0.017 & 0.019 & 0.018 & 0.018 & 0.02 \\
\hline $\mathrm{D}$ & 0.057 & 0.057 & 0.055 & 0.053 & 0.055 & 0.055 & 0.039 & 0.051 & 0.058 & 0.055 & 0.055 & 0.05 \\
\hline $\mathrm{E}$ & 0.094 & 0.095 & 0.091 & 0.088 & 0.091 & 0.091 & 0.085 & 0.085 & 0.097 & 0.091 & 0.091 & 0.09 \\
\hline $\mathrm{F}$ & 0.057 & 0.057 & 0.055 & 0.053 & 0.055 & 0.055 & 0.051 & 0.051 & 0.058 & 0.055 & 0.055 & 0.05 \\
\hline $\mathrm{G}$ & 0.132 & 0.134 & 0.127 & 0.158 & 0.127 & 0.127 & 0.118 & 0.119 & 0.069 & 0.127 & 0.127 & 0.12 \\
\hline $\mathrm{H}$ & 0.132 & 0.123 & 0.164 & 0.158 & 0.164 & 0.164 & 0.152 & 0.153 & 0.175 & 0.164 & 0.164 & 0.16 \\
\hline I & 0.094 & 0.095 & 0.091 & 0.088 & 0.091 & 0.091 & 0.166 & 0.085 & 0.097 & 0.091 & 0.091 & 0.10 \\
\hline $\mathbf{J}$ & 0.132 & 0.134 & 0.127 & 0.123 & 0.127 & 0.127 & 0.118 & 0.119 & 0.136 & 0.127 & 0.127 & 0.13 \\
\hline $\mathrm{K}$ & 0.057 & 0.057 & 0.055 & 0.053 & 0.055 & 0.055 & 0.051 & 0.051 & 0.058 & 0.055 & 0.055 & 0.05 \\
\hline
\end{tabular}

We calculated the consistency index, or $C I$, as follows:

$$
C I=\frac{\lambda_{\max }-n}{n-1}=\frac{11.05-11}{11-1}=0.005
$$

The consistency of the matrix can be verified using the consistency ratio, $C R$ of $C I$, with the appropriate value from Table 6 . For a matrix size of 13 , using Table 6 , we determined the appropriate value of the random consistency ratio $(R I)$ to be 1.52 . The consistency ratio $C R$ is defined in Equation 17.

$$
C R=\frac{C I}{R I}=\frac{0.005}{1.520}=0.003
$$

Next, we calculated the priority preference vector for the real estate agent, resident, and farmer for the rapid development scenario and constructed Table 7 . We calculated the priority vector of preferences for the regional authority, real estate, resident, and farmer agents for the green land protection scenario.

The weightings of the driving factors were equal to combined preferences $\left(P R^{k}\right)$ of the regional authority, real estate developer, resident, and farmer agents as determined by Equation 4. We calculated the weightings of the driving factors for the rapid development and green land protection scenarios. For the rapid development scenario, the weightings of the driving factors were as follows:

$$
W=[5.35,2.14,0.14,0.31, \cdots, 1.46]
$$

For the green land protection scenario, the weightings of the driving factors are listed as follows:

$$
W=[0.80,0.69,2.95,2.39, \cdots, 0.82]
$$

For the baseline scenario, the agent preferences did not impact on the weightings of factor $k$. For the rapid development and green land protection scenarios, the combined preferences (Eq. 5 ) impacted on the weightings of factor $k$.

By using Equation 3, we calculated the urban development probability of every cell for the rapid development and green land protection scenarios.
Table 7. The standardized preferences of regional authority, real estate developer, resident, and farmer agents on the driving factors for the rapid development scenario.

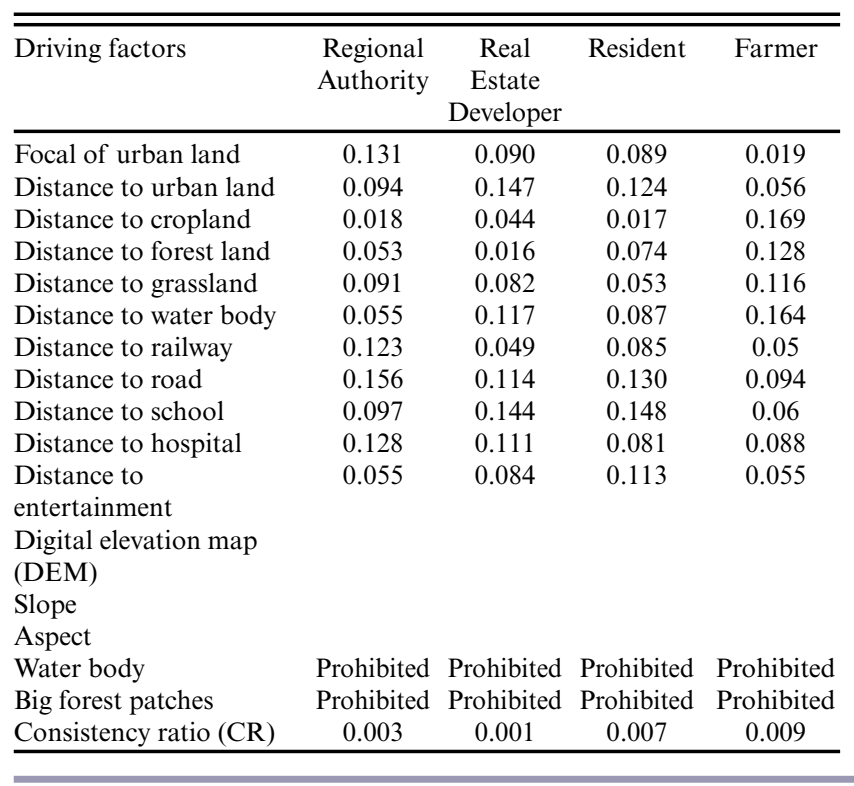

The likelihood of urban development within all districts and cities is equal to the conversion probability.

$$
\Delta U L_{k}(t)=\sum_{i j} P_{i j k}(t)
$$

\section{Model evaluation}

Kappa is calculated on the basis of the projected and observed values over the entire region (Congalton and Green 1999). The equation used is as follows:

$$
\text { Kappa }=\frac{P_{o}-P_{c}}{1-P_{c}}
$$

Where $P_{o}$ is the correct percentage of the model output, and $P_{c}$ is the expected correct percentage.

The value of Kappa ranges from 0 to 1 . Although there is no universally accepted standard, a Kappa value greater than 0.8 is 
considered to be an indication of a strong agreement between the predicted and observed maps (Congalton and Green 1999, Tian et al. 2011b).

We simulated urban development under the three scenarios in 2005 and further evaluated the model by comparing an artificial interpretation of the land-use map with the simulated land-use map for 2005 using the Kappa coefficient (Congalton and Green 1999, Pontius et al. 2001, Tian et al. 2011b; see Online Resource 1). We computed the Kappa coefficient using the settings for the baseline scenario, rapid development scenario, and green land protection scenario, resulting in Kappa values of 0.8444, 0.7350, and 0.7336 , respectively. The Kappa coefficient calculation was based on the baseline scenario settings, suggesting a strong agreement between the predicted and observed maps. The result for the baseline scenario was closer to the empirical land-use map of 2005 than the rapid development and green land protection scenarios. The results for the rapid development and green land protection scenarios were considered to be two possible development modes, according to agent preferences.

\section{Simulation of urban development in the Guangzhou metropolitan region}

Urban development in Guangzhou under three scenarios, i.e., baseline, rapid development, and green land protection scenarios, was simulated.

\section{Baseline scenario:}

For the baseline scenario, the simulation was based on previous development. Agent preferences did not influence the weighting of the driving factors. The spatial strategy derived from urban planning and policies was not considered for urban expansion. The probability of urban development was decided by the $\beta$ values (Table 3). Four land-use types were converted into urban land. There was a prohibition against converting the water bodies and large patches of forest. Under this scenario, $597.69 \mathrm{~km}^{2}$ land, i.e., $364.51 \mathrm{~km}^{2}$ of cropland, $47.75 \mathrm{~km}^{2}$ of forest, $150.49 \mathrm{~km}^{2}$ of rural residential land, and $4.03 \mathrm{~km}^{2}$ of other land, would be converted into urban land during the period of 2005 2020 (Fig. 4).

\section{Rapid development scenario:}

For this scenario, the agents gave more attention to economic development. The weightings of variables related to infrastructure, such as the distance to schools, hospitals, entertainment centers, railways, and roads, increased whereas the weightings of other variables, such as the distance to forest, grassland, and water bodies, decreased. However, the weightings of the physical factors, such as digital elevation map (DEM) and slope, did not change much. From a rapid development perspective, roads and railways are the most important infrastructure. Schools, hospitals, and entertainment centers will be beneficial to residents. These factors stimulated economic development. According to this scenario, $657.46 \mathrm{~km}^{2}$ of land, i. e., $400.96 \mathrm{~km}^{2}$ of cropland, $52.53 \mathrm{~km}^{2}$ of forest, $165.54 \mathrm{~km}^{2}$ of rural residential land, and $4.43 \mathrm{~km}^{2}$ of other land, would be converted into urban land during the period of 2005 2020 (Fig. 5).

\section{Green land protection scenario:}

For this scenario, the agents pay more attention to green land protection. The weights of the variables, such as the distance to forest, grassland, and water bodies, increased whereas other factors, such as distance to schools, hospitals, entertainment centers, roads, and railways, decreased. The weightings of physical factors, such as the DEM and slope, did not change. From the green land protection perspective, the forest, grassland, and water bodies were given primary protection. According to this scenario, 537.92 $\mathrm{km}^{2}$ of land would be converted into urban land during the period of 2005 2020 (Fig. 6). During this period, approximately 217.47 $\mathrm{km}^{2}$ of cropland, $180.85 \mathrm{~km}^{2}$ of forest, $100.45 \mathrm{~km}^{2}$ of rural residential land, and $39.14 \mathrm{~km}^{2}$ of other land would be converted into urban land.

Fig. 4. The simulation of urban development in Guangzhou metropolitan region in 2020 for baseline scenario.

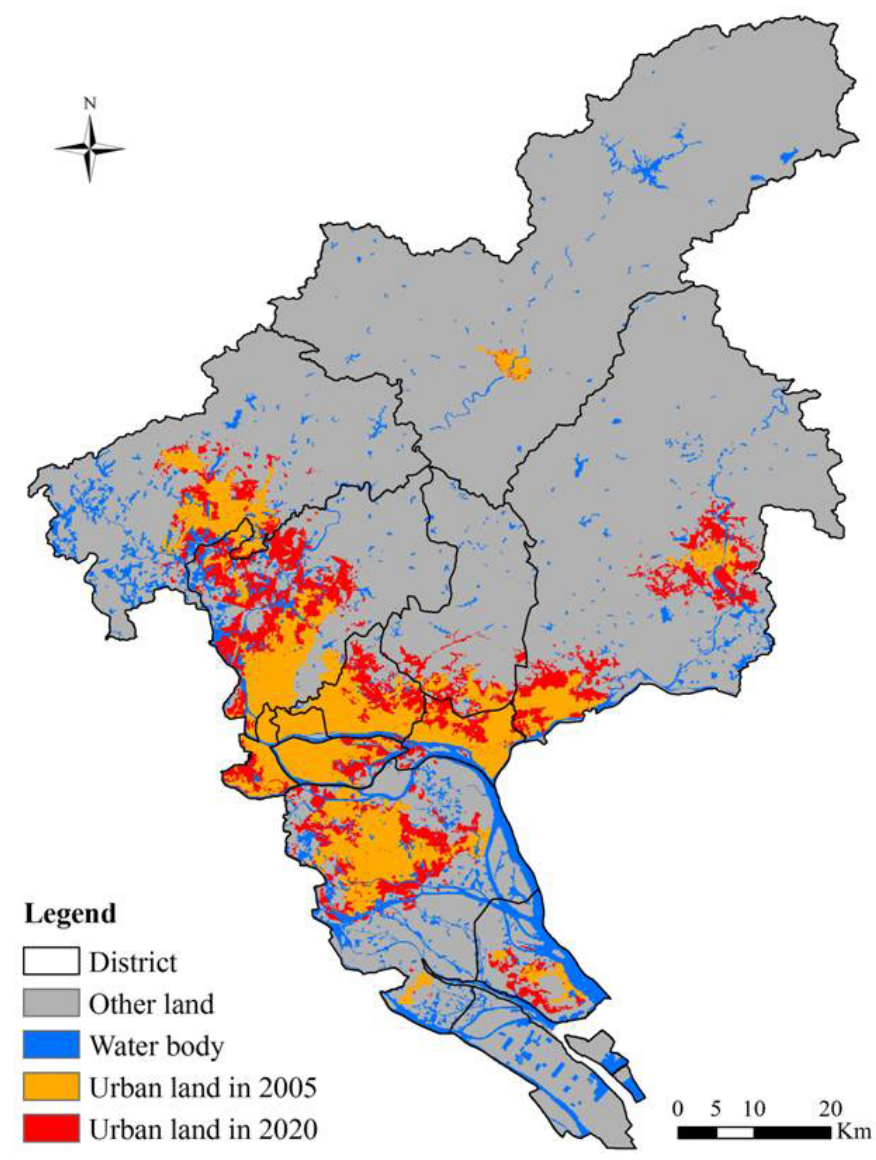

Metrics used in the comparisons among the simulated scenarios Landscape metrics have been widely used to quantify the spatial and temporal patterns of urban dynamics (Tian et al. 2007a, $b$, 2011a, b, Wu et al. 2011). To compare the urbanization pattern of the simulated scenarios for Guangzhou, spatial metrics were calculated using Fragstats software (McGarigal and Marks 1995). Through the analysis of landscape metrics, we compared the spatial pattern of urbanization for the different scenarios in the Guangzhou metropolitan region.

The spatial metrics describe the size, connection between the urban patches, and the complexity of the urban form. The spatial metrics 
for different periods in Guangzhou can help to trace trends in the dynamic change of landscape patterns during urbanization. We compared the landscape metrics of the three scenarios from the patch shape and aggregation level of the urban landscape. The selected spatial metrics were the edge density (ED), parameter area ratio (PARA), and contiguity index (CONTIG; see Appendix 1).

Fig. 5. The simulation of Guangzhou metropolitan region in 2020 for rapid development scenario.

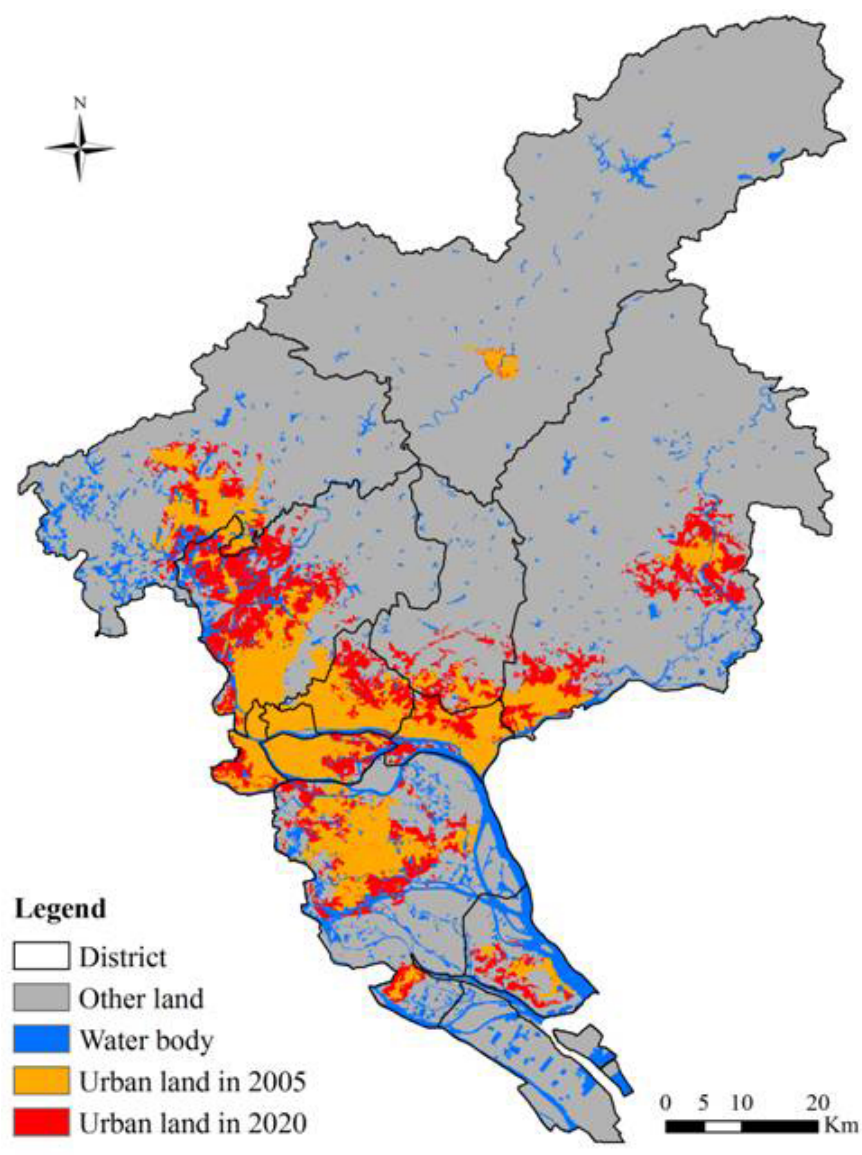

We compared the landscape metrics of the three scenarios in 2020. Among the three scenarios, the ED was lowest and the CONTIG was highest in the rapid development scenario (Appendix 1) and, therefore, the scenario resulted in the lowest fragmentation of urban patches. In contrast, the ED was highest and the CONTIG was lowest in the green land protection scenario (Appendix 1). In the rapid development scenario, agent preferences were more focused on economic development, whereas the agents gave more attention to ecological environment in the green land protection scenario. Therefore, in the rapid development scenario, the distance to urban land, schools, hospitals, entertainment centers, railways, and roads were more important in determining the direction of urban expansion (Table 7). New urban land was more associated with the above factors and encroached on the forest, grassland, and cropland. However, forest, grassland, and cropland restricted urban land sprawl because of the agent preferences in the green land protection scenario. New urban land expanded far away from forest, grassland, and cropland, and was therefore more dispersed and fragmented than in the rapid development scenario. The differences in the PARA and CONTIG between the two urban development scenarios also confirmed the agent-based model. The ED and PARA were lowest in the rapid development scenario, which indicated that the shape of the urban patches was more regular in this scenario. However, in the green land protection scenario, the ED and PARA were highest, which indicated that the urban patches became more irregular. In the rapid development scenario, agent preferences encouraged new urban land to sprawl around previous constructions, including the urban center, schools, hospitals, entertainment centers, railways, and roads, and, therefore, the whole urban area become more compact. In contrast, in the green land protection scenario, agent preferences resulted in protection for forest, grassland, cropland, and water, which ensured that new urban land did not always sprawl around previous construction because of the restrictions in developing forest, grassland, cropland, and water. Therefore, the urban area was not regular, as in the rapid development scenario, but more scattered.

Fig. 6. The simulation of Guangzhou metropolitan region in 2020 for green land protection scenario.

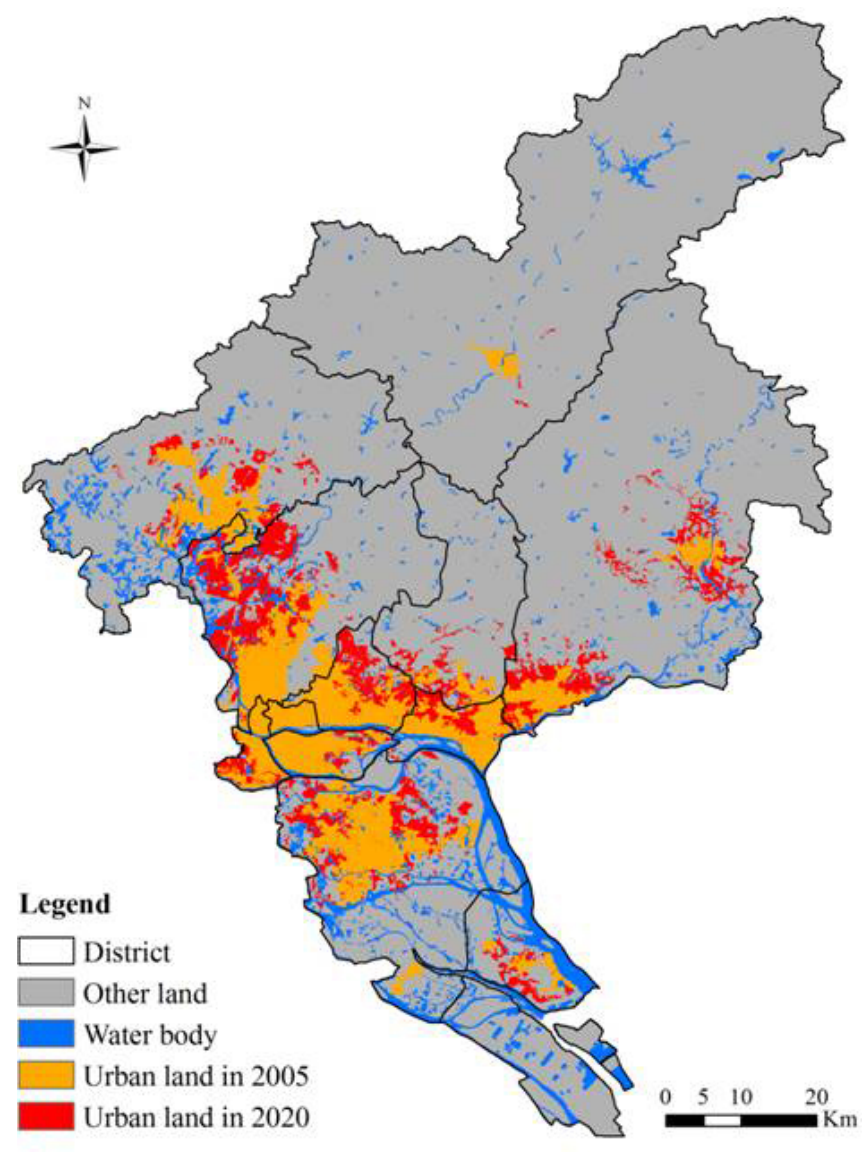

\section{DISCUSSION}

The urbanization of metropolitan regions is a complex and human-dominated process. The traditional approaches to 
studying urbanization often ignore human behavior, decisionmaking processes, and policies. The ABM is an approach that has received significant attention in recent years as a way to link the biophysical and socioeconomic characteristics of a system (Tian et al. 2011b). It is particularly appropriate when there is an important interdependence between agents and their environment. We simulated the behavior and decision making of regional authorities, real estate developers, residents, and farmers in this model by using AHP. The rules were based on a priori knowledge related to agent preferences. Pairwise comparisons were used to acquire agent preferences and their interactions to determine the driving factors. Parameter combination and choice reflects complex decision-making processes and policies. The model parameters have a big impact on simulation results.

At the same time, urban planning and policies have been used in the simulation of urban development. Spatial strategy policies will affect the direction of urban development in a metropolitan area. The development of urban land in the Panyu and Nansha districts is projected to increase under the current spatial strategy. In our model, three policy scenarios of baseline, rapid development, and green land protection were simulated. Scenario analysis is a useful tool for studying different policies. Sustainable development strategies have been incorporated into agent-based modeling to correctly define the behavior of agents ( $\mathrm{Li}$ and Liu 2008). Urban planning and policies have been incorporated into the model to better understand the spatial pattern of urban expansion for policy makers.

In future studies, several areas need to be further investigated. First, the classification of agents should be more precise, and should consider the demands of different age or income groups. This is mainly considered with regard to the appearance of adverse urbanization in some large and medium-sized cities during periods of growth in their urbanization. Second, there is a need for more scientific methods, which could be used to quantify the decision-making behavior of agents in most Chinese cities because of the lack of detailed spatial data. The integration of an agent-based spatial model and a detailed questionnaire survey could improve simulation performance if such spatial information were available.

Responses to this article can be read online at: http://www.ecologyandsociety.org/issues/responses. php/6909

\section{Acknowledgments:}

This study was funded by National Key Technology R\&D Program of China during the Twelfth Five-Year Plan Period (2012 BAC13 B01) and by the National Natural Science Foundation of China under grant 41071357.

\section{LITERATURE CITED}

Al-S. Al-Harbi, K. M. 2001. Application of the AHP in project management. International Journal of Project Management 19 (1):19-27. http://dx.doi.org/10.1016/S0263-7863(99)00038-1

An, L., M. Linderman, J. Qi, A. Shortridge, and J. Liu. 2005. Exploring complexity in a human-environment system: an agent- based spatial model for multidisciplinary and multiscale integration. Annals of the Association of American Geographers 95(1):54-79. http://dx.doi.org/10.1111/j.1467-8306.2005.00450.x

Bandini, S., S. Manzoni, and G. Vizzari. 2009. Agent based modeling and simulation: an informatics perspective. Journal of Artificial Societies and Social Simulation 12(4):4. http://jasss.soc. surrey.ac.uk/12/4/4.html

Basharin, G. P., A. N. Langville, and V. A. Naumov. 2004. The life and work of A. A. Markov. Linear Algebra and its Applications 386(15): 3-26. http:/dx.doi.org/10.1016/j.laa.2003.12.041

Bousquet, F., and C. Le Page. 2004. Multi-agent simulations and ecosystem management: a review. Ecological Modelling 176(3): 313-332. http://dx.doi.org/10.1016/S0304-3800(04)00094-8

Collins, J. B., and C. E. Woodcock. 1994. Change detection using the Gramm-Schmidt transformation applied to mapping forest mortality. Remote Sensing of Environment 50:267-279. http://dx. doi.org/10.1016/0034-4257(94)90076-0

Congalton, R. G., and K. Green. 1999. Assessing the accuracy of remote sensed data. Lewis, New York, New York, USA.

Fung, T., and E. LeDrew. 1988. The determination of optimal threshold levels for change detection using various accuracy indices. Photogrammetric Engineering and Remote Sensing 54, 1449-1454.

Fung, T. 1990. An assessment of TM imagery for land-cover change detection. IEEE Transactions on Geoscience and Remote Sensing 28:681-684. http://dx.doi.org/10.1109/TGRS.1990.572980

Geoghegan, J., S. C. Villar, P. Klepeis, P. M. Mendoza, Y. OgnevaHimmelberger, R. R. Chowdhury, B. L. Turner, II, and C. Vance. 2001. Modeling tropical deforestation in the Southern Yucátan peninsular region: comparing survey and satellite data. Agriculture, Ecosystems and Environment 85:25-46. http://dx.doi. org/10.1016/S0167-8809(01)00201-8

Gobin, A., P. Campling, and J. Feyen. 2001. Logistic modelling to derive agricultural land use determinants: a case study from southeastern Nigeria. Agriculture, Ecosystems and Environment 89:213-228. http://dx.doi.org/10.1016/S0167-8809(01)00163-3

Goldstone, R. L., and M. A. Janssen. 2005. Computational models of collective behavior. Trennds in Cognitive Sciences 9 (9):424-430. http://dx.doi.org/10.1016/j.tics.2005.07.009

Gong, J.-Z., Y.-S. Liu, B.-C. Xia, and G.-W. Zhao. 2009. Urban ecological security assessment and forecasting, based on a cellular automata model: a case study of Guangzhou, China. Ecological Modelling 220:3612-3620. http://dx.doi.org/10.1016/j.

ecolmodel.2009.10.018

Guangdong Statistics Bureau. 2006. Guangdong statistics yearbook of 2006. China Statistical Yearbooks, Beijing, China.

Guangzhou Urban Planning Bureau. 2000. General strategic conceptual plan. Guangzhou Urban Planning Formation and Research Center, Guangzhou, P. R. China.

He, C., N. Okada, Q. Zhang, P. Shi, and J. Li. 2008. Modelling dynamic urban expansion processes incorporating a potential model with cellular automata. Landscape and Urban Planning 86 (1):79-91. http://dx.doi.org/10.1016/j.landurbplan.2007.12.010 
Heath, B., R. Hill, and F. Ciarallo. 2009. A survey of agent-based modeling practices (January 1998 to July 2008). Journal of Artificial Societies and Social Simulation 12(4):9. http://jasss.soc. surrey.ac.uk/12/4/9.html

Janssen, M. 1998. Use of complex adaptive systems for modeling global change. Ecosystems 1:457-463. http://dx.doi.org/10.1007/ $\underline{\mathrm{s} 100219900041}$

Janssen, M. A., B. H. Walker, J. Langridge, and N. Abel. 2000. An adaptive agent model for analysing co-evolution of management and policies in a complex rangeland system. Ecological Modelling 131:249-268. http://dx.doi.org/10.1016/ $\underline{\mathrm{S} 0304-3800(00) 00256-8}$

Ji, C. Y., Q. Liu, D. Sun, S. Wang, P. Lin, and X. Li. 2001. Monitoring urban expansion with remote sensing in China. International Journal of Remote Sensing 22(8):1441-1455. http:/ dx.doi.org/10.1080/01431160117207

Lambin, E. F., X. Baulies, N. E. Bockstael, G. Fischer, T. Krug, R. Leemans. 2000. Land-use and land-cover change (LUCC), implementation strategy. IGBP Report 48, IHDP Report 10. Scientific Steering Committee and International Project Office of LUCC, Stockholm, Sweden.

Lempert, R. 2002. Agent-based modeling as organizational and public policy simulators. Proceedings of the National Academy of Sciences 99(3):7195-7196. http://dx.doi.org/10.1073/pnas.072079399

Li, X., and X. Liu. 2007. Defining agents' behaviors to simulate complex residential development using multicriteria evaluation. Journal of Environmental Management 85(4):1063-1075. http:/dx. doi.org/10.1016/i.jenvman.2006.11.006

Li, X., and X. Liu. 2008. Embedding sustainable development strategies in agent-based models for use as a planning tool. International Journal of Geographical Information Science 22 (1):21-45. http://dx.doi.org/10.1080/13658810701228686

Ligtenberg, A., A. K. Bregt, and R. van Lammeren. 2001. Multiactor-based land use modeling: spatial planning using agents. Landscape and Urban Planning 56(1-2):21-33. http://dx.doi. org/10.1016/S0169-2046(01)00162-1

Ligtenberg, A., M. Wachowicz, A. K. Bregt, A. Beulens, and D. L. Kettenis. 2004. A design and application of a multi-agent system for simulation of multi-actor spatial planning. Journal of Environmental Management 72(1-2):43-55. http://dx.doi.org/10.1016/ j.jenvman.2004.02.007

Liu, J., M. Liu, D. Zhuang, Z. Zhang, and X. Deng. 2003. Study on spatial pattern of land-use change in China during 1995-2000. Science in China Series D: Earth Sciences 46:373-384.

Liu, J., M. Liu, H. Tian, D. Zhuang, Z. Zhang, W. Zhang, X. Tang, and X. Deng. 2005a. Spatial and temporal patterns of China's cropland during 1990-2000: an analysis based on Landsat TM data. Remote Sensing of Environment 98:442-456. http://dx. doi.org/10.1016/j.rse.2005.08.012

Liu, J., H. Tian, M. Liu, D. Zhuang, J. M. Melillo, and Z. Zhang. 2005b. China's changing landscape during the 1990s: large-scale land transformations estimated with satellite data. Geophysical Research Letter 32:L02405. http://dx.doi.org/10.1029/2004GL021649
Loibl, W., and T. Toetzer. 2003. Modelling growth and densification processes in suburban regions-simulation of landscape transition with spatial agents. Environmental Modelling and Software 18:553-563. http://dx.doi.org/10.1016/S1364-8152 (03)00030-6

McGarigal, K., and B. J. Marks. 1995. FRAGSTATS: spatial pattern analysis program for quantifying landscape structure. U.S. Department of Agriculture, Forest Service, Pacific Northwest Research Station, Portland, Oregon, USA.

Matthews, R. B., N. G. Gilbert, A. Roach, J. G. Polhill, and N. M. Gotts. 2007. Agent-based land-use models: a review of applications. Landscape Ecology 22:1447-1459. http://dx.doi. org/10.1007/s10980-007-9135-1

Parker, D. C, S. M. Manson, M. A. Janssen, M. J. Hoffmann, and P. Deadman. 2003. Multi-agent system for the simulation of landuse and land-cover change: a review. Annals of the Association of American Geographers 93(2):314-337. http://dx.doi. org/10.1111/1467-8306.9302004

Pontius, R. G., J. D. Cornell, and C. A. S. Hall. 2001. Modeling the spatial pattern of land-use change with GEOMOD2: application and validation for Costa Rica. Agriculture, Ecosystems and Environment 85:191-203. [online] URL: http:// www.clarku.edu/ rpontius/pontius etal 2001 aee.pdf

Quarmby, N. A., and J. L. Cushnie. 1989. Monitoring urban land cover change at the urban fringe from SPOT HRV imagery in south-east England. International Journal of Remote Sensing 10:953-963. http://dx.doi.org/10.1080/01431168908903937

Saaty, T. L. 1980. The analytical hierarchy process: planning, priority setting, resource allocation. McGraw-Hill, New York, New York, USA.

Sengupta, R. R., and D. A. Bennet. 2003. Agent-based modelling environment for spatial decision support. International Journal of Geographical Information Science 17(2):157-180. http://dx.doi. org/10.1080/713811747

Serneels, S., and E. F. Lambin. 2001. Proximate causes of landuse change in Narok District, Kenya: a spatial statistical mode. Agriculture, Ecosystems and Environment 85:65-81.

Seto, K. C., and R. K. Kaufmann. 2003. Modeling the drivers of urban land use change in the Pearl River Delta, China: integrating remote sensing with socioeconomic data. Land Economics 79 (1):106-121. http://dx.doi.org/10.2307/3147108

Skibniewski, M. J., and L.-C. Chao. 1992. Evaluation of advanced construction technology with AHP method. Journal of Construction Engineering and Management 118(3):577-593. http://dx.doi.org/10.1061/(ASCE)0733-9364(1992)118:3(577)

Tian, G., J. Liu, and Z. Zhang. 2002. Urban functional structure characteristics and transformation in China. Cities 19(4):243-248. http://dx.doi.org/10.1016/S0264-2751(02)00021-5

Tian, G., J. Liu, Y. Xie, Z. Yang, D. Zhuang, and Z. Niu. 2005. Analysis of spatio-temporal dynamic pattern and driving forces of urban land in China in 1990s using TM images and GIS. Cities 22(6):400-410. http://dx.doi.org/10.1016/j.cities.2005.05.009 
Tian, G., Z. Yang, and Y. Zhang. 2007a. The spatio-temporal dynamic pattern of rural residential land in China in the 1990s using Landsat TM images and GIS. Environmental Management 40(5):803-813.http://dx.doi.org/10.1007/s00267-006-0048-6

Tian, G., Z. Yang, and Y. Xie. 2007b. Detecting spatiotemporal dynamic landscape patterns using remote sensing and the lacunarity index: a case study of Haikou City, China. Environment and Planning B: Planning and Design 34(3):556-569. http://dx.doi. org/10.1068/b3155

Tian, G., J. Wu, and Z. Yang. 2010. Spatial pattern of urban functions in the Beijing metropolitan region. Habitat International 34(2):249-255. http://dx.doi.org/10.1016/j. habitatint.2009.09.010

Tian, G., J. Jiang, Z. Yang, and Y. Zhang. 2011a. The urban growth, size distribution and spatio-temporal dynamic pattern of the Yangtze River Delta megalopolitan region, China. Ecological Modelling 222(3):865-878. http://dx.doi.org/10.1016/j. ecolmodel.2010.09.036

Tian, G., Y. Ouyang, Q. Quan, and J. Wu. 2011b. Simulating spatiotemporal dynamics of urbanization with multi-agent systems - a case study of the Phoenix metropolitan region, USA. Ecological Modelling 222(5):1129-1138. http://dx.doi.org/10.1016/ j.ecolmodel.2010.12.018

Torrens, P M. 2003. Cellular automata and multi-agent systems as planning support tools. Pages 205-222 in S. Geertman and J. Stillwell, editors. Planning support systems in practice: advances in spatial science. Springer, Berlin, Germany. http://dx.doi. org/10.1007/978-3-540-24795-1 12

Torrens, P. M., and I. Benenson. 2005. Geographic automata systems. International Journal of Geographical Information Science 19:385-412. http://dx.doi.org/10.1080/13658810512331325139

Triantakonstantis, D, and G. Mountrakis. 2012. Urban growth prediction: a review of computational models and human perceptions. Journal of Geographic Information System 4 (6):555-587. http://dx.doi.org/10.4236/jgis.2012.46060

Turner, II, B. L. 1994. Local faces, global flows: the role of land use and land cover in global environmental change. Land Degradation and Rehabilitation 5:71-78. http://dx.doi.org/10.1002/ $\underline{\text { ldr.3400050204 }}$

Verburg, P. H., G. H. J. de Koning, K. Kok, A. Veldkamp, and J. Bouma. 1999. A spatial explicit allocation procedure for modelling the pattern of land use change based upon actual land use. Ecological Modelling 116:45-61. http://dx.doi.org/10.1016/ $\underline{\text { S0304-3800(98)00156-2 }}$

Verburg, P. H., W. Soepboer, A. Veldkamp, R. Limpiada, V. Espaldon, and S. A. Mastura. 2002. Modeling the spatial dynamics of regional land use: the CLUE-S model. Environmental Management 30(3):391-405. http://dx.doi.org/10.1007/s00267-002-2630$\underline{x}$

Waddell, P. 2002. UrbanSim: modeling urban development for land use, transportation, and environmental planning. Journal of the American Planning Association 68(3):297-314. http://dx.doi. org/10.1080/01944360208976274
Wang, F. 1993. A knowledge-based vision system for detecting land changes at urban fringes. IEEE Transactions on Geoscience and Remote Sensing 31:136-145. http://dx.doi.org/10.1109/36.210454

Wu, F. 1998. SimLand: a prototype to simulate land conversion through the integrated GIS and CA with AHP-derived transition rules. International Journal of Geographical Information Science 12(1):63-82. http://dx.doi.org/10.1080/136588198242012

Wu, F. 2002. Calibration of stochastic cellular automata: the application to rural-urban land conversions. International Journal of Geographical Information Science 16(8):795-818. http://dx.doi. org/10.1080/13658810210157769

Wu, F., and C. J. Webster. 1998. Simulation of land development through the integration of cellular automata and multicriteria evaluation. Environment and Planning B: Planning and Design 25:103-126. http://dx.doi.org/10.1068/b250103

Wooldridge, M., and N. R. Jennings. 1995. Intelligent agents: theory and practice. Knowledge Engineering Review 10:115-152. http://dx.doi.org/10.1017/S0269888900008122

Xie, Y., M. Batty, and K. Zhao. 2007. Simulating emergent urban form using agent-based modeling: Desakota in the SuzhouWuxian region in China. Annals of the Association of American Geographers 97(3):477-495. http://dx.doi.org/10.1111/ j.1467-8306.2007.00559.x

Yeh, A. G.-O., and X. Li. 1998. Sustainable land development model for rapid growth areas using GIS. International Journal of Geographical Information Science 12(2):169-189. http://dx.doi. org/10.1080/136588198241941

Yu, X. J., and C. N. Ng. 2007. Spatial and temporal dynamics of urban sprawl along two urban-rural transects: a case study of Guangzhou, China. Landscape and Urban Planning 79:96-109. http://dx.doi.org/10.1016/j.landurbplan.2006.03.008

Zipperer, W. C., J. Wu, R. V. Pouyat, and T. A. Pickett. 2000. The application of ecological principles to urban and urbanizing landscapes. Ecological Applications 10(3):685-688. http://dx.doi. org/10.1890/1051-0761(2000)010[0685:TAOEPT]2.0.CO;2 
Metrics Description $\quad$ Formula

$\begin{array}{ccc}\text { Baseline } & \text { Rapid } & \text { Green } \\ \text { scenario } & \begin{array}{c}\text { development } \\ \text { scenario }\end{array} & \text { land } \\ & \text { protection }\end{array}$

scenario protection

PD equals the number of patches of the corresponding

patch class divided by total landscape area $\left(\mathrm{m}^{2}\right)$,

multiplied by 10,000 and 100 (to convert to $1 \mathrm{~km}^{2}$ ). It

PD expresses the number of patches on a per unit area

basis that facilitates comparisons among landscapes of

$$
P D=\frac{N}{A}(10000)(100)
$$

varying size. According to the meaning, the maximum density of patches of a single class is attained when every other cell is of that focal class.

LSI is landscape shape index, $E$ is total length of perimeter of urban land, $A$ is the area of study area. $L S I=1$, when the landscape consists of a single

LSI square or maximally compact (i.e., almost square)

$$
L S I=\frac{0.25 E}{\sqrt{A}}
$$
patch of the corresponding type. LSI increases without limit as the patch type becomes more disaggregated.

Aggregation index is calculated from an adjacency matrix, which shows the frequency with which

AI different pairs of patch types (including like adjacencies between the same patch type) appear

$$
\mathrm{AI}=\left[\sum_{i=1}^{m}\left(\frac{g_{i i}}{\max \rightarrow g_{i i}}\right) P_{i}\right](100)
$$
side-by-side on the map.

Perimeter-area fractal dimension indicates the relationship between the area and perimeter of the urban patch. A fractal dimension greater than 1 for a 2-dimensional landscape mosaic indicates a departure from a Euclidean geometry. PAFRAC approaches 1 for shapes with very simple perimeters such as squares, and approaches 2 for shapes with highly convoluted,

$$
P A F R A C=\frac{\left[n_{i} \sum_{j=1}^{n}\left(\ln p_{i j} \cdot \ln a_{i j}\right)\right]-\left[\left(\sum_{j=1}^{n} \ln p_{i j}\right)\left(\sum_{j=1}^{n} \ln a_{i j}\right)\right]}{\left(n_{i} \sum_{j=1}^{n} \ln p_{i j}{ }^{2}\right)-\left(\sum_{j=1}^{n} \ln p_{i j}\right)^{2}}
$$

